\title{
Jeanice Brooks
}

\section{Ritterroman und höfisches Lied - Die weibliche Stimme im französischen Salon des späten 16. Jahrhunderts}

Die folgenden Verse, die erstmals 1548 veröffentlicht wurden, werden in jedem heutigen Leser eine Saite zum Klingen bringen, der schon einmal eine Nacht über einem Bestseller verbracht hat:

Et si quelqu'un à le lire s'espreuve,

Pour la douceur, et soulas qu'il y treuve,

Il en perdra le boire et le menger,

Il laissera à son profit songer,

Puys quand aura quelque peu de sejour,

Y passera et la nuyt et le jour,

$\mathrm{Ne}$ delaissant de lire incessament,

Tant que iceluy ait leu entierement.

Und wenn es jemand zu lesen beginnt,

wird er über der Süße und Leichtigkeit, die er darin findet,

Essen und Trinken vergessen.

Er wird aufhören, an seine Geschäfte zu denken, und wenn er ein wenig Zeit hat, wird er darüber Nacht und Tag verbringen und nicht aufhören, unentwegt darin zu lesen, bis er es ganz gelesen hat. ${ }^{1}$

* Dieser Beitrag ist die gekürzte Version einer längeren englischen Studie: „Chivalric Romance, Courtly Love and Courtly Song: Female Vocality and Feminine Desire in the World of >Amadis de Gauler", in: Musical Voices of Early Modern Women: Many-Headed Melodies, hrsg. von Thomasin LaMay, Aldershot (in Vorbereitung). Mein Dank gilt Matthew Head, Ellen Harris und Marian Rothstein für ihren Rat und für Kommentare zu einer früheren Fassung, und Linda Maria Koldau für die Übersetzung ins Deutsche.

1 Michel Sévin d'Orléans, Einleitungsgedicht zu Le huitiesme livre d'Amadis de Gaule, übersetzt von Nicolas de Herberay des Essarts, Paris 1548, zit. nach Hugues Vaganay, Amadis en franfais. Essai de bibliographie, Florenz 1906, Reprint Genf 1970, S. 75. Das Gedicht wurde zusammen mit dem Buch veröffentlicht und mag daher als Werbemaßnahme abgetan werden; doch waren selbst diejenigen, die dem Werk ablehnend gegenüberstanden, gezwungen, seine Popularität einzugestehen. So gibt François de La Nouẽ zu, der Roman sei am Hofe Heinrichs II. von Frankreich so beliebt gewesen, dass seine Leser jedem ins Gesicht gespuckt hätten, der gewagt hätte, es schlecht zu machen. Siehe François de La Noué, Discours politiques $\varepsilon t$ militaires (1581), hrsg. von Frank E. Sutcliffe, Genf 1967 (Textes littéraires français, 132), S. 162. 
Der Roman, der seine Leser derart fesselte, war Amadis de Gaule, ein umfangreicher Ritterroman und die literarische Sensation Frankreichs im 16. Jahrhundert. Er beruht auf einem spanischen Roman, der so reißenden Absatz fand, dass Franz I. seinem Höfling Nicolas de Herberay des Essarts befahl, eine Übersetzung anzufertigen. ${ }^{2}$ Herberay des Essarts erweiterte seine Vorlage beträchtlich, um sie dem französischen Geschmack anzupassen. Gleichzeitig schuf er einen lyrischen Prosastil, der das zeitgenössische Bemühen um eine Bereicherung der französischen Sprache widerspiegelt. Dieser neue Stil fand so großen Anklang, dass er sich zum Modell höfischer Sprache entwickelte, und die französische Sprache wurde um ein neues Verb bereichert: "amadiser", d. h. "in einer lieblich gezierten Weise sprechen ${ }^{3}{ }^{3}$ Nach dem ersten, 1540 erschienenen Band veröffentlichte Herberay des Essarts bis zu seinem Tod im Jahr 1552 sieben weitere Bände des Romans. Zahlreiche Schriftsteller führten die Arbeit fort bis zu Buch 24, das 1615 publiziert wurde. Das ganze Jahrhundert hindurch erschienen Neuausgaben früherer Bände, und Sammlungen mit Auszügen sorgten für eine weite Verbreitung der meist bewunderten Passagen. ${ }^{4}$

Glaubt man den zeitgenössischen Zeugen, so hat fast jeder, der - oder die in Frankreich im 16. Jahrhundert zu lesen verstand, Amadis de Gaule gelesen. Doch ging der uneingeschränkte Erfolg der ersten Jahrzehnte allmählich in ein zwiespältiges Urteil über. Obwohl der Roman noch immer weit verbreitet war, wurden seine erotischen Passagen zur Zielscheibe von Moralisten, während Verfasser von militärischer Literatur die fantastische Unwahrscheinlichkeit der

2 Zum Hintergrund der französischen Ausgabe vgl. Yves Girauds Einleitung zu Le premier livre d'Amadis de Gaule, hrsg. von Hugues Vaganay, 2., erweiterte Aufl., hrsg. von Yves Giraud, 2 Bde., Paris 1986, S. 5f. Die Biographie von Herberay des Essarts ist am ausfuihrlichsten dargestellt bei Michel Simonin, "La disgrâce d'`Amadis« ", in: Studi Francesi 28 (1984), S. 1-35.

3 Zu Herberay des Essarts' Stil als literarisches Modell vgl. Véronique Benhaïm, "Les sThresors d'Amadis« «, und Mireille Huchon, "Amadis. >Parfaicte idée de nostre langue françoise «, in: Les Amadis en France au XVT siècle, hrsg. von Robert Aulotte, Paris 2000, S. 164-180 bzw. S. 183-200.

4 Die ersten vier Bände der französischen Ausgabe richten sich nach der Vorlage von Garci Rodríguez de Montalvos spanischem Roman; spätere Bände orientieren sich an Fortsetzungen von anderen spanischen (später auch italienischen) Autoren. R. Aulotte (Les Amadis en France, wie Anm. 3, S. 209-211) bietet eine Liste früher französischer Ausgaben und zeigt ihre Abhängigkeit von den spanischen Originalen auf. Vgl. auch Hugues Vaganay, "Les éditions in $-8^{\circ}$ de l’Amadis« français«, in: Revue hispanique 85 (1929), S. 1-53; ders., Amadis en français (wie Anm. 1), und die Bibliographie zu Buch 1 in Le premier livre (wie Anm. 2), S. 24-26. Zu den Ausschnittsammlungen oder »thresors« vgl. V. Benhaïm, Les sThresors« (wie Anm. 3), und Hugues Vaganay, "Les trésors d'`Amadis: essai de bibliographie«, in: Revue hispanique 57 (1923), S. 115-126. 
Schlachten-Episoden kritisierten. Gleichzeitig brachte man Amadis immer enger mit einem weiblichen Publikum in Verbindung, einer Leserschaft, die von Druckern und Übersetzern gezielt anvisiert wurde. ${ }^{5}$

Dieser Wandel in der Rezeption des Romans geschah zur gleichen Zeit, als Frauen in Drucken mit höfischen Liedern hervorzutreten begannen. In den frühen 1570er-Jahren überlagerte sich die Welt von Amadis mit derjenigen des höfischen Liedes: Sowohl Liederbücher als auch neue Übersetzungen des Romans entstanden im Umfeld literarisch-musikalischer Salons, die von Frauen als Mäzeninnen, Leserinnen und Musikerinnen geführt wurden. Die Verbindung zwischen Produktion und Rezeption setzt sich im Inhalt fort, denn häufig spiegeln die Liedtexte gesprochene Passagen des Romans wider. Somit erscheint der Roman als potenziell machtvolles Instrument, um das französische Lied an einem wichtigen Wendepunkt seiner Geschichte zu erfassen, als man nämlich die populären Strophenformen - bislang als Voix de ville bekannt - mit zunehmendem Eifer bei Hofe zu kultivieren begann.

Amadis de Gaule hat viel mit seinen mittelalterlichen und spanischen Vorbildern gemeinsam, ${ }^{6}$ weicht jedoch in seiner stärkeren Betonung der Liebesepisoden von ihnen ab. Diese Episoden sind stark von neoplatonischen und neopetrarkistischen Idealen geprägt. Der Amadis in Herberay des Essarts' Übersetzung ist nicht nur der vollkommene Krieger, sondern auch der vollkommene Liebhaber. Seine Beziehung zu seiner Angebeteten Oriane versinnbildlicht die Suche nach spiritueller Vollkommenheit durch irdische Liebe - ein Konzept, das Lesern von Ficino, Castiglione, Leone Ebreo vertraut gewesen sein dürfte. Diese Eigenschaften des französischen Amadis haben eine besondere Auswirkung auf die weiblichen Figuren des Romans. Da Frauen - außer als Vorwand - in Kampfszenen nur selten auftreten, erlaubt ihnen der größere Anteil an Liebesepisoden im Roman auch in höherem Maße, an der Handlung teilzuhaben. Zudem verleiht die mediale Funktion von Frauen in der neoplatonischen Liebes-

5 Zur Leserschaft des Amadis vgl. Marian Rothstein, Reading in the Renaissance: Amadis de Gaule and the Lessons of Memory, Newark 1999, S. 114-124.

6 Vgl. Le premier livre (wie Anm. 2), S. 9f,; M. Rothstein, Reading (wie Anm. 5), S. 64-70, und John J. O'Connor, Amadis de Gaule and its Influence on Elizabethan Literature, New Brunswick 1970, S. $85-129$. 
theorie ihrer Rolle im Amadis - verglichen mit den Frauenfiguren in früheren Romanen - ein größeres Gewicht. ${ }^{7}$

Da der Roman durchgängig neoplatonische Ideale widerspiegelt, überrascht es nicht, dass der Anstoß zu einer neuen Übersetzungen des Amadis in den frühen 1570er-Jahren aus dem Kreis um Claude-Catherine de Clermont, Comtesse de Retz, kam. Ihr Salon ist in der Literaturwissenschaft als Brennpunkt für eine neue Welle neoplatonischen und neopetrarkistischen Schrifttums in den 1570erJahren bekannt. ${ }^{8}$ So spielte er auch in der Geschichte des französischen Romans Amadis eine wichtige Rolle. Die 1571 erschienene Übersetzung des 13. Buches ist Catherine gewidmet; der Herausgeber Jacques Gohory legt im Vorwort dar, dass er die Übersetzung auf ihre Bitte hin angefertigt hat. ${ }^{9}$

Desgleichen lässt sich die Comtesse mit einflussreichen französischen Musikdrucken des gleichen Zeitraums in Verbindung bringen, die der jungen Gattung des Air de cour gewidmet sind (siehe Tabelle 1 im Anhang, S. 108f.). ClaudeCatherine de Clermont ist Widmungsträgerin von Guillaume Costeleys Musique von 1570 und, noch weit bedeutsamer, von Adrian Le Roys Livre d'airs de cour

7 Zur neoplatonischen Umdeutung des Amadis vgl. M. Rothstein, Reading (wie Anm. 5), S. 52 60. Catherine Mary Hampton, Chastity: A Literary and Cultural Icon of the French SixteenthCentury Court, Ph.D. diss. University of Durham 1996, S. 201-215, legt dar, inwiefern der Roman den neoplatonischen Schlüsselbegriff der Keuschheit illustriert.

8 Zur Biographie der Catherine de Clermont vgl. Madame Michel Jullien de Pommerol née Marie-Henriette de Montéty, Albert de Gondi, Maréchal de Retz, Genf 1953 (Travaux d'humanisme et renaissance, 5), S. 195-218, und Christie Ellen St-John, The Salon vert of the Maréchale de Retz: A Study of a Literary Salon in Sixteenth-Century France, Ph.D. diss. Vanderbilt University 1999. Zu ihrem Salon vgl. auch Jacques Lavaud, Philippe Desportes (1546-1606). Un poette de cour au temps des derniers Valois, Paris 1936, S. 72-106; Louis Clark Keating, Studies on the Literary Salon in France, 1550-1615, Cambridge, Mass. 1941 (Harvard Studies in Romance languages, 16), S. 103-125; Jeanice Brooks, "La comtesse de Retz et l'air de cour des années 1570«,

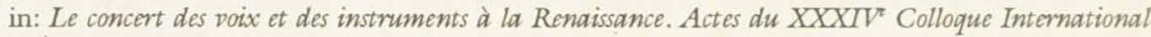
d'Études Humanistes, Tours ... 1991, hrsg. von Jean-Michel Vaccaro, Paris 1995, S. 299-316; und Rosanna Gorris, » गJe veux chanter d'amour la tempeste et l'orager. Desportes et les simitations« d'Arioste", in: Philippe Desportes (1546-1606). Un poète presque parfait entre Renaissance et Classicisme, hrsg. von Jean Balsamo, Paris 2000 (Actes et colloques du Centre de Philologie et de Littératures Romanes de la Faculté des Lettres de l'Université de Strasbourg, 62), S.173-211.

9 Le trezieme livre d'Amadis de Gaule, Paris 1571. Gohory, ein Humanist und Alchemist mit starken Neigungen zum Okkultismus, hatte fast zwanzig Jahre zuvor bereits frühere Bände der Romanfolge übersetzt; dass er nach einem so langen Zeitraum wieder auf den Roman zurückkam, unterstützt seine Angabe, die Übersetzung von 1571 gehe auf einen Auftrag zurück. Vgl. Le Dixiesme livre d'Amadis de Gaule, Paris 1552, und L'Onzieme livre d'Amadis de Gaule, Paris 1554. Gohorys Übersetzung von Buch 13 war der erste neue Band, der seit Guillaurne Auberts Übersetzung des zwölften Buchs (1556) erschien. Zur Biographie von Gohory vgl. Rosanna Gorris, »Pour une lecture stéganographique des >Amadis de Jacques Gohory«, in: Les Amadis en France (wie Anm. 3), S. 127-156. 
miz sur le luth von $1571 .{ }^{10}$ Diese Sammlung enthält Bearbeitungen beliebter höfischer Lieder für Gesang und Laute. Die meisten davon waren bereits in mehrstimmiger Bearbeitung in Nicolas de La Grottes Chansons von 1569 erschienen. Das Livre d'airs de cour ist ein Folgeband zu einer anderen Sammlung, die Le Roy ebenfalls Catherine gewidmet hatte, ein Lehrbuch für Laute, das vermutlich erstmals 1570 erschien. ${ }^{11}$ In seinem Vorwort zum Livre d'airs de cour bezeichnet sich Le Roy als »serviteur hereditaire" (»Erbdiener «) von Catherines Familie. ${ }^{12}$ Er hebt hervor, dass die Texte und Melodien der Lieder Catherine bereits vertraut seien und sie demnach ein umso größeres Vergnügen an den neuen Bearbeitungen haben werde. ${ }^{13}$

Die langjährige Verbindung zwischen Catherine und Le Roy lässt vermuten, dass auch Lieder aus anderen Sammlungen des Komponisten zu Catherines Repertoire gehörten (siehe Tabelle 1 im Anhang). Kurz nach der Gründung ihres Musikverlags im Jahr 1551 veröffentlichten Le Roy \& Ballard eine Serie

10 Musique de Guillaume Costeley, organiste ordinaire et pallet de chambre, du treschretien et tresinvincible Roy de France, Paris 1570; teilweise ediert in Guillaume Costeley, Musique, hrsg. von Henry Expert Paris 1896-1904 (Les maitres musiciens de la Renaissance française, 3, 18 und 19), Reprint New York o. J.; zu Stïcken, die in Experts Edition nicht enthalten sind, siehe Guillaume Costeley, Selected Chansons, hrsg. von Jane A. Bernstein, New York 1989 (The Sixteenth-Century Chanson, 8), und Adrian Le Roy, Livre d'airs de cour miz sur le luth, Paris 1571, ediert in: Chansons au luth et airs de cour français du XVIe siècle, hrsg. von Lionel de La Laurencie, Adrienne Mairy und Geneviève Thibault, Paris 1934, Reprint ebda. 1976 (Publications de la Societé Française de Musicologie, 1.3/4). Vgl. J. Brooks, La comtesse de Retz (wie Anm. 8), dort auf S. 313f. eine vollständige Liste der Widmungen an Catherine de Clermont und ihren Ehemann Albert de Gondi.

11 Das erste Lautenlehrbuch von Le Roy erschien wahrscheinlich erstmals 1567 in Frankreich; das einzige erhaltene Exemplar ist eine englische Übersetzung aus dem Jahr 1568. Das Catherine gewidmete Lautenlehrbuch kam vermutlich 1570 heraus, also kurz vor dem Lipre d'airs de cour. Erhalten ist es lediglich als englische Übersetzung aus dem Jahr 1574, die Material aus allen drei Drucken enthält: A briefe and plaine Instruction to set all musicke of divers Tunes in Tableture for the Lute, London 1574. Vgl. Adrian Le Roy, Les instructions pour le luth, hrsg. von Jean Jacquot, Pierre-Yves Sordes und Jean-Michel Vaccaro, 2 Bde., Paris 1977; eine Übersicht über die Veröffentlichungsgeschichte findet sich dort in Bd. 1, S. ix-xiv.

12 Der Hintergrund dieser Anspielung ist im Vorwort zum Lautenlehrbuch erläutert: Le Roy geht auf seine Dienstzeit bei Catherines Vater, Claude de Clermont, Baron de Dampierre, ein und ruft in Erinnerung, wie er über dem Leichnam von Dampierre weinte, als dieser in der Schlacht von 1545 umkam. Vgl. A. Le Roy, Les instructions (wie Anm. 11), Bd. 1, S. 2f., und Chansons au luth et airs de cour français (wie Anm. 10), S. xxvi und lvi.

13 Die Bücher sind im Detail besprochen bei Jeanice Brooks, Courtly Song in Late SixteenthCentury France, Chicago 2000, S. 13-31. Die Beziehung des Lirre d'airs de cour zu Nicolas de La Grottes Chansons de P. de Ronsard, Ph. Desportes et autres (Paris: Le Roy \& Ballard, 1569) ist dargestellt in: Jonathan Le Cocq, The Status of Le Roy's Publications for Voice and Lute or Guitar, in: The Lute 35, 1995, S. 4-27, und Jonathan Le Cocq, French Lute Song, 1529-1643 Diss. Oxford 1997, S. 11-20. 
von Musikdrucken mit Musik für Zupfinstrumente, in Tabulatur gesetzt von Le Roy. Darunter befindet sich das Second livre de guiterre von 1552, eine Sammlung mit Liedern für Gitarre und Solostimme, die Le Roy \& Ballard gleichzeitig als mehrstimmige Version in Pierre Certons Premier livre de chansons veröffentlichten. ${ }^{14}$ Wie in der Tabelle zu sehen ist, kam Le Roy als Verleger und Bearbeiter in den nächsten zwei Jahrzehnten wiederholt auf diese Stücke zurück. Kurz nachdem er das Livre d'airs de cour im Jahr 1571 Catherine gewidmet hatte, veröffentlichte Le Roy sein Premier livre de chansons en forme de vau de ville. Dieses besteht aus neuen mehrstimmigen Bearbeitungen der gleichen strophischen Lieder, die er in den 1550er- und 1560er-Jahren veröffentlicht hatte. Im Premier livre de chansons sind sie als Version für Gitarre und in mehrstimmig-vokaler Bearbeitung enthalten. Wie seit langem bekannt ist, spielen diese Drucke eine zentrale Rolle in der Geschichte des zunächst als »voix de ville« bekannten und 1571 von Le Roy in »air de cour umbenannten französischen Liedes. ${ }^{15}$ Die Drucke, die Le Roy zu Beginn der 1570er-Jahre Catherine de Clermont widmete, waren einfach die neuesten Produkte einer lebenslangen Beschäftigung mit Musik in diesem Stil. Le Roys "Erbdienerschaft " gegenüber Catherines Familie macht es wahrscheinlich, dass sie seine Aufführungen dieser Lieder bereits als Kind erlebt hat. Sein ihr gewidmetes Lautenlehrbuch könnte darauf hinweisen, dass er sogar ihr Lehrer war. Le Roys Bemerkung im Livre d'airs de cour über Catherines Vertrautheit mit den Stücken bezieht sich demnach auf ein Repertoire an höfischen Liedern, das beiden wohl geläufig war und oft in Catherines Salon aufgeführt wurde.

Ein Bindeglied zwischen den Musikdrucken und dem Kreis um Catherine de Clermont ist somit Adrian Le Roy, der Verleger von Costeleys Buch und der Bearbeiter von weiteren Liedersammlungen. Ein weiteres solches Bindeglied ist Jacques Gohory, der ein Widmungsgedicht zu Costeleys Sammlung und ein Vorwort zu Le Roys nicht erhaltenem Lautenlehrbuch beisteuerte. Gohory war einerseits ein langjähriger Bekannter Le Roys, andererseits ein regelmäßiger

14 Paris 1555 (1556 neuer Stil). Es handelt sich um die zweite Auflage eines nicht erhaltenen Musikdrucks, der erstmals zwischen dem Erscheinen des Premier livre de tabulature de guiterre im September 1551 und des Tiers livre de tabulature de guiterre von 1552 erschien.

15 Die weite Verbreitung dieser Lieder geht aus ihrer Übernahme in die Sammeldrucke hervor, die in Jehan Chardavoines Kompendium der beliebten einstimmigen Voix de ville in der Tabelle im Anhang aufgeführt sind (Le recueil des plus belles et excellentes chansons en forme de voix de ville, hrsg. von Jehan Chardavoine, Paris 1576; Reprint Genf 1980). Die Bedeutung dieser Sammeldrucke in der Entwicklung dieser Gattung wird am ausfuihrlichsten dargelegt bei Jane Ozenberger Whang, From >Voix de ville to , Air de cours: The Strophic Chanson, c. 1545-1575, Ph.D. diss. University of North Carolina 1981. 
Gast im Salon der Comtesse de Retz. ${ }^{16}$ In seinem Vorwort erwähnt Gohory ein anderes Projekt, das er fast abgeschlossen hat: seine Übersetzung des 13. Buches von Amadis de Gaule. Diese unverblümte Eigenwerbung rechtfertigt sich zumindest teilweise durch Gohorys Annahme, dass die Käuferinnen und Käufer des Lautenlehrbuches auch Interesse am Roman haben würden. Zumindest eine Käuferin: Catherine de Clermont. Um mit den Worten von Marian Rothstein zu sprechen, die eine rezeptionsorientierte Studie über Amadis veröffentlicht hat: Catherine ist eine »manifeste Leserin" des 13. Buchs von Amadis, von Costeleys Musique, des Lautenlehrbuches und der Airs de cour miz sur le luth. ${ }^{17}$ Indem sie ihr die verschiedenen Drucke widmeten, visieren Le Roy and Gohory Catherine als angepeilte Leserin und Interpretin ihres Inhalts an. Schwieriger ist, andere Leserinnen und Leser zu identifizieren, die nicht explizit in den Texten erwähnt werden. Amadis hat zwar mehr Hinweise auf seine Leserschaft hinterlassen als die meisten Werke des 16. Jahrhunderts, doch bieten die Musikdrucke kaum eine Spur. Dennoch lassen Besitzvermerke in erhaltenen Exemplaren erkennen, dass die Besitzerinnen und Besitzer meistens zu dem gleichen Kreis von Musikern, Literaten, Höflingen und Beamten gehörten wie Costeley, Le Roy, Gohory, Catherine de Clermont und die Personen in ihrem Umfeld. ${ }^{18}$

16 Im Lautenlehrbuch schrieb Gohory, er sei von »the affection which from my youth upwards ... I have borne, to Musicke ... [and] the old familiaritie which it hath caused me to have with the Aucthor of this present Booke« inspiriert worden; vgl. die Edition des Vorwortes bei François Lesure und Geneviève Thibault, Bibliographie des éditions d'Adrian Le Roy et Robert Ballard (1551-1598), Paris 1955, S. 33-35.

17 »Manifeste Leser« sind Personen, denen Bücher gewidmet sind oder die auf den einleitenden Seiten als Autoren oder Rezipienten erscheinen. Vgl. M. Rothstein, Reading (wie Anm. 5), S. 114-117.

18 Eine Sammlung von Superius-Stimmbüchern in F-Pn, Rés.Vmf.13, die Abschriften von Pierre Certons Premier livre und Second livre de chansons (Ausgabe von 1564) enthält, gehörte Louis Cramoisy, einem Tasteninstrumentenspieler im Haushalt von François d'Anjou, dem Bruder des Königs. Ein Satz Stimmbücher aus der Sammlung von Alfred Cortot (jetzt GB-Lbl, k.11.e.3) gehörte anfangs einer der Gräfinnen von La Tillières; die Besitzvermerke lassen nicht erkennen, ob dies Charlotte Chabot war, die 1578 Jacques de Tillières heiratete, oder Catherine de Bassompierre, die 1608 die Frau von Tanneguy de Tillières wurde. Die Veneur de Tillières waren eine angesehene Familie des Hofadels; die Stimmbücher enthalten Nicolas La Grottes Chansons und das Second livre in der Ausgabe von 1569. Le Roys Livre d'airs de cour ist in einem einzigen Exemplar erhalten (B-Br, Fétis 2379), das im frühen 17. Jahrhundert Hugues Picardet gehörte, einem angesehenen burgundischen Schriftsteller und Hofbeamten. Vgl. dazu Laurent Guillo, "Les livres de musique de Hugues Picardet (1560-1641), procureur général au Parlement de Bourgogne«, in: Bulletin du Bibliophile 1 (2001), S. 58-85. Der Dichter Rémy Belleau, der Catherine ein Sonett widmete, besaß eine Laute, eine Cister und ein Dutzend Musikdrucke (leider enthält Belleaus Inventar keine genauere Beschreibung dieser Bücher; vgl. Madeleine 
Aber die Beziehungen zwischen dem Amadis und den Sammlungen mit höfischen Liedern sind weit komplexer als dass sie nur eine gemeinsame Leserschaft beträfen. Viele der Stücke in den Liederbüchern stellen lyrische Betrachtungen über die stereotypen Situationen des Romans dar. Sie verwenden das gleiche Vokabular, die gleiche Sprache und die gleiche Konstellation von Personen und Ereignissen. Das bedeutet, dass sie nicht nur gleichermaßen den Gesetzen des literarischen Marktes verhaftet sind, sondern auch den dichterischen Gesetzen von Ausdruck und Bildlichkeit. Diese inhaltlichen Parallelen wie auch die deutlichen Überschneidungen in Produktion und Rezeption lassen vermuten, dass der Roman Referenzpunkte anbot, um den Französinnen im 16. Jahrhundert das Verständnis der Lieder zu erschließen - umgekehrt ermöglichen uns diese Referenzpunkte heute, die Bedeutung des Liedes und des Romans für ein weibliches Publikum zu entschlüsseln.

In manchen Fällen wird die Beziehung zwischen Lied und Roman durch explizite Verweise oder offensichtliche Parallelen hergestellt, wenn etwa Charaktere aus Amadis in den Liedtexten vorkommen oder Lieder aus zeitgenössischen Musikdrucken in Romanen zitiert werden. ${ }^{19}$ Bedeutsamer für meine Fragestellung sind jedoch die Fälle, in denen Liedtexte aus dem Umkreis von Catherines Salon typische Situationen aus den Romanen aufnehmen und Passagen aus den Reden der Romanfiguren widerspiegeln. Diese Anklänge treten unverkennbar in verschiedenen lyrischen Textsorten auf, darunter auch in Liedern, die eine Frauenperspektive widerspiegeln. Der heftig umstrittene Raum, den die verbale Präsenz von Frauen in dieser Zeit einnahm, lässt diese Situationen, in denen weibliche Figuren sprechen oder singen, als besonders aufschlussreich für die zeitgenössische Sicht weiblicher Sexualität erscheinen.

In den Amadis-Romanen äußern weibliche Figuren ihre Gefühle in Szenen, die in geringfügiger Variation den ganzen Romanzyklus hindurch wiederkehren. Von Liebe entflammt - meist auf dem ersten Blick -, drücken sie ihre Sehnsucht nach dem Geliebten aus, doch stellen sich der Erfüllung ihrer Liebe, zumindest in den Beziehungen der Hauptfiguren, fast immer beträchtliche Hindernisse in den Weg. Umherziehende Ritter haben eine unglückselige Nei-

Jurgens, Ronsard et ses amis. Documents du Minutier Central des Notaires de Paris, Paris 1985, S. 219 und 32).

19 So endet "C'est de la peine dure«, ein Lied von Le Roy, das sowohl in seinem Gitarrenbuch von 1552 als auch in seinem Premier livre en forme de vau de ville von 1573 enthalten ist, mit einer Strophe, in welcher der männliche Sprecher seinen treuen Dienst an seiner Dame dem Dienst des Amadis an Oriane vergleicht. Costeleys Musique (siehe Selected Chansons, wie Anm. 10, S. 132-134) enthält eine strophische französische Übersetzung des Hohenliedes; diese weist eindeutige Anklänge an eine entsprechende Übersetzung auf, die Gohory im 13. Buch von Amadis (wie Anm. 9) einfügte (fol. $336^{\mathrm{r}}-337^{\mathrm{T}}$ ). 
gung, sich in Abenteuer zu stürzen, sodass weibliche Klagen über den Abschied des Geliebten an der Tagesordnung sind. Ein weitaus gewichtigeres Hindernis ist dagegen die soziale Kontrolle, wie sie durch den höfischen Ehrenkodex ausgeübt wird. In den Dialogen müssen die Frauen häufig und mit Nachdruck ihre Ehre gegenüber den Versuchen der Männer, diesen Ehrenkodex zu unterminieren, verteidigen. Doch steht ihr Widerstand in der Regel im Widerspruch zu ihren eigenen Wünschen. So entsteht eine weitere Art der Klage, in der die Unnachgiebigkeit des Ehrenkodex beklagt wird, versagt er doch den Frauen, ihre den Wünschen der Verehrer durchaus gleichrangigen - Bedürfnisse zu befriedigen. Zu guter Letzt wird die Frau fast ausnahmslos durch die unübertroffenen Tugenden des Mannes und durch ihre eigene Leidenschaft besiegt. Die Liebenden finden endlich die sexuelle Erfüllung, die als beiderseits gewollt und beiderseits befriedigend dargestellt wird. Obwohl sie meist schon vorab Treue-Eide schwören und Heiratsversprechen geben, spielen sich die meisten erotischen Episoden in den Romanen außerhalb der formalen Ehestruktur ab. Und selbst wenn aus solchen Begegnungen ein uneheliches Kind hervorgeht, werden sie in der Regel als tugendhaft dargestellt. ${ }^{20}$

Im Standardmuster des Romans werden diesen exemplarischen Liebesbeziehungen Negativmodelle gegenübergestellt, in denen Frauen ihre Liebhaber unklug gewählt oder ihren sexuellen Gelüsten zu rasch nachgegeben haben. Meistens beweinen diese Frauen ihr Unglück und klagen die treulosen Männer voll Bitterkeit an. In anderen Fällen wird solchen Paaren die sexuelle Befriedigung gewährt, und sie trennen sich ohne ernsthafte Konsequenzen. Während heterosexuelle Beziehungen, ob erfolgreich oder nicht, den größten Anteil der Beziehungen im Amadis ausmachen, gewährt der Roman auch gelegentliche Einblicke in andere Formen der Sexualität, sei es durch autoerotische oder gleichgeschlechtliche Episoden. ${ }^{21}$

20 Siehe M. Rothstein, Reading (wie Anm. 5), S. 138: "Herberay's Amadis ... generally considers consensual sex between nobles as a laudable activity whose results, often male offspring, were generally pleasing to God in the great scheme of things.« Diese Haltung ist in den mittelalterlichen Romanen gang und gäbe. Hier erhält sie eine neoplatonische Wendung: Die physische Vereinigung der treuen Liebenden ist Teil der spirituellen Vereinigung, die wiederum eine Voraussetzung für die göttliche Offenbarung darstellt.

21 Einige solcher Begegnungen sind dargestellt bei Winfried Schleiner, "Laughter and Challenges to the Other in the French >Amadis de Gaules «, in: Sixteenth Century Journal 32 (2001), S. 91-107, und ders., " >Le feu cachés: Homosocial Bonds Between Women in a Renaissance Romance«, in: Renaissance Quarterly 45 (1992), S. 293-311; eine musikalische Verkleidungsepisode in Buch 11 - zwei heranwachsende junge Männer verkleiden sich als Lautensängerinnen - werde ich in einer weiteren, in Vorbereitung befindlichen Studie erörtern. 
Die Palette erotischer Beziehungen und möglicher Ergebnisse ist demgemäß recht weit, doch wird das weibliche Verlangen in fast allen Situationen in ähnlicher Weise dargestellt. Frauen äußern erotische Gefühle ausschließlich in privatem Umfeld - einer Vertrauten, dem Liebhaber oder sich selbst gegenüber sowie in Briefen, deren mögliche Entdeckung durch Dritte oft Grund zur Sorge gibt. Das Rendezvous der Liebenden findet immer heimlich statt, da sie sich bewusst sind, dass die sie umgebende Gesellschaft ihre Beziehung als illegitim verdammen wird, ungeachtet ihrer Rechtschaffenheit im Rahmen der göttlichen Ordnung. Die weiblichen Figuren äußern meist das Bedürfnis, die Liebe schweigend zu erleiden und ihre Leidenschaft vor der äußeren Welt, ja sogar vor dem Geliebten zu verbergen. Mit anderen Worten: Weibliche Sexualität wird rhetorisch als Schweigen verschlüsselt; die Leserinnen und Leser erleben das Verlangen der sich äußernden Person nur als etwas, das den anderen Romanfiguren vorenthalten wird. Als Frauen von hoher Geburt lassen die Romanfiguren ihren Wunsch erkennen, zeitgenössischen Frauenidealen zu entsprechen. In Anstandsbüchern der Zeit wird Schweigen meist als zentrale weibliche Tugend hervorgehoben: die Kontrolle ihrer Zunge als Pendant zur Kontrolle ihres Körpers sowie als Zeichen ihrer unbefleckten Keuschheit. Höfische Texte, die eine verbale Präsenz von Frauen rehabilitieren wollten, mussten sich der vorherrschenden Assoziation weiblicher Verbalität mit sexueller Aktivität in der zeitgenössischen Kultur stellen. Die verbale Aktivität von Frauen musste demnach in einer Weise beschrieben werden, dass ihre sexuelle Integrität erhalten blieb. ${ }^{22}$ Im Verbot, das eigene Verlangen auszudrücken, klingt auch das neoplatonische Ziel einer rationalen Kontrolle des Körpers an, die als Ideal für Frauen und Männer galt. Gleichermaßen verdeutlicht es die Sozialisation des Neoplatonismus, wie er durch Castiglione und seine Nachfolger propagiert wurde: Die Betonung liegt auf der Verstellung als Teil einer im Wesentlichen höfischen Ästhetik. Indem sie die Zwänge des Ehrenkodex beklagen und das Schweigen thematisieren, wird diese Kontrolle des eigenen Äußerungsvermögens durch die Frauengestalten im Amadis gleichzeitig beschworen und herausgefordert.

Wenn wir uns den Liederbüchern zuwenden, entdecken wir, dass in den musikalischen Äußerungen aus weiblicher Perspektive oft Textpassagen der Frauenfiguren aus den Romanen widerhallen. Klagen von Frauen, die von ihrem Liebhaber verlassen wurden, ihn durch äußere Trennung oder Tod verloren haben, kommen mehrfach in den Liedsammlungen vor. Ein gutes Beispiel bietet etwa »Mon coeur ma chere vie«. Das Gedicht stammt möglicherweise von Catherine

$22 \mathrm{Zu}$ einer detaillierteren Darstellung dieses Sachverhaltes und seiner Wirkung auf das Sprechen und Singen von Frauen bei Hofe vgl. J. Brooks, Courtly Song (wie Anm. 13), S. 191-254. 
de Clermont persönlich; seine Vertonung wurde in Le Roys Livre d'airs de cour aufgenommen. Klagelieder gehören einer erheblich weiter gefassten Kultur weiblichen Trauerns an: Der Topos weiblicher Trauer ließ sich in einer Vielzahl sozialer und politischer Kontexte instrumentalisieren. ${ }^{23}$ Darüber hinaus wurde das Klagelied auch als Mittel eingesetzt, Verlangen auszudrücken - eine Rolle, die es häufig in Romanen und Liedern einnimmt.

Frauenklagen als Mittel, die Auswirkungen erotischen Verlangens zu umschreiben, finden sich im Amadis in großer Zahl; sie gehören zu den längsten und emotional lebhaftesten Passagen unter den Frauenreden. Als Beispiel möge hier Orianes Klage in Buch 2 dienen, in der sie die Einsamkeit ihres Lebens im Wachen ohne Amadis mit den Freuden seiner nächtlichen Besuche im Traume vergleicht, oder die Klage der Lucelle in Buch 8, die ihre gegenwärtige Bitterkeit über die hinterlistige Täuschung durch ihren Liebhaber den vorhergehenden gemeinsamen Freuden gegenüberstellt. Ein sprechendes Beispiel einer gesungenen Klage als Ausdruck des Verlangens, wie es sich ähnlich in Amadis findet, ist das Lied »Est-ce pas mort» (siehe folgende Seite). Erstmals erschien das Lied in Adrian Le Roys mehrstimmiger Bearbeitung in der revidierten Neuauflage des Second livre de chansons von 1564 und in weiteren Neuauflagen nochmals 1569 und $1577 .{ }^{24}$

In diesem Klagelied geht es um den Konflikt zwischen Verlangen und Ehre, zwischen dem Drang, sich zu äußern, und der Unmöglichkeit, dies zu tun. Diese Spannungen haben die Sängerin in den - erotisch aufgeladenen - Zustand der Todesnähe versetzt, wie er im Refrain »LIEBE denkt, ich schlafe, doch sterbe ich« zum Ausdruck kommt (siehe Text 1 im Anhang, S. 110f.). Ihre Schilderung der physischen Folgen ihres unerfüllten Verlangens erinnert an den $\mathrm{Zu}$ stand der Marfire in Buch 13 des Amadis (siehe Text 2 im Anhang, S. 112). Die Beschreibung ihrer Selbstbefriedigung als Ersatz für die imaginären Liebko-

23 Vgl. die Ausgabe von Early Music 27.3 (August 1999), die unter dem Titel "Laments« Klageliedern von Frauen im 16. und frühen 17. Jahrhundert gewidmet ist. In meinem dortigen Beitrag "Catherine de Médicis, snouvelle Artémises: Women's Laments and the Virtue of Grief«, S. 419-435 und in meinem Buch Courtly Song (wie Anm. 13), S. 209-227, untersuche ich "Mon coeur ma chere vie« im Kontext von Catherine de Médicis politischen Zielen. Eine weitere Studie zur Nutzung des Klageliedes für politische Ziele bietet Kate van Orden, »Female >Complaintes: Laments of Venus, Queens, and City Women in Late Sixteenth-Century Francek, in: Renaissance Quarterly 54 (2001), S. 801-845.

24 "Est-ce pas mort" war auch in reinen Text-Chansonniers der 1570er- und 1580er-Jahre weit verbreitet - dort figuriert ist es unter der Rubrik »Complainte de l'amoureuse craintive mourant d'amours (»Klage einer geängstigten verliebten Frau, die vor Liebe stirbt«) - wie auch im Sommaire de tous les recueils de chansons, tant amoureuses, rustiques que musicales, Lyon 1579, fol. $61^{\mathrm{r}}-62^{\mathrm{r}}$. 

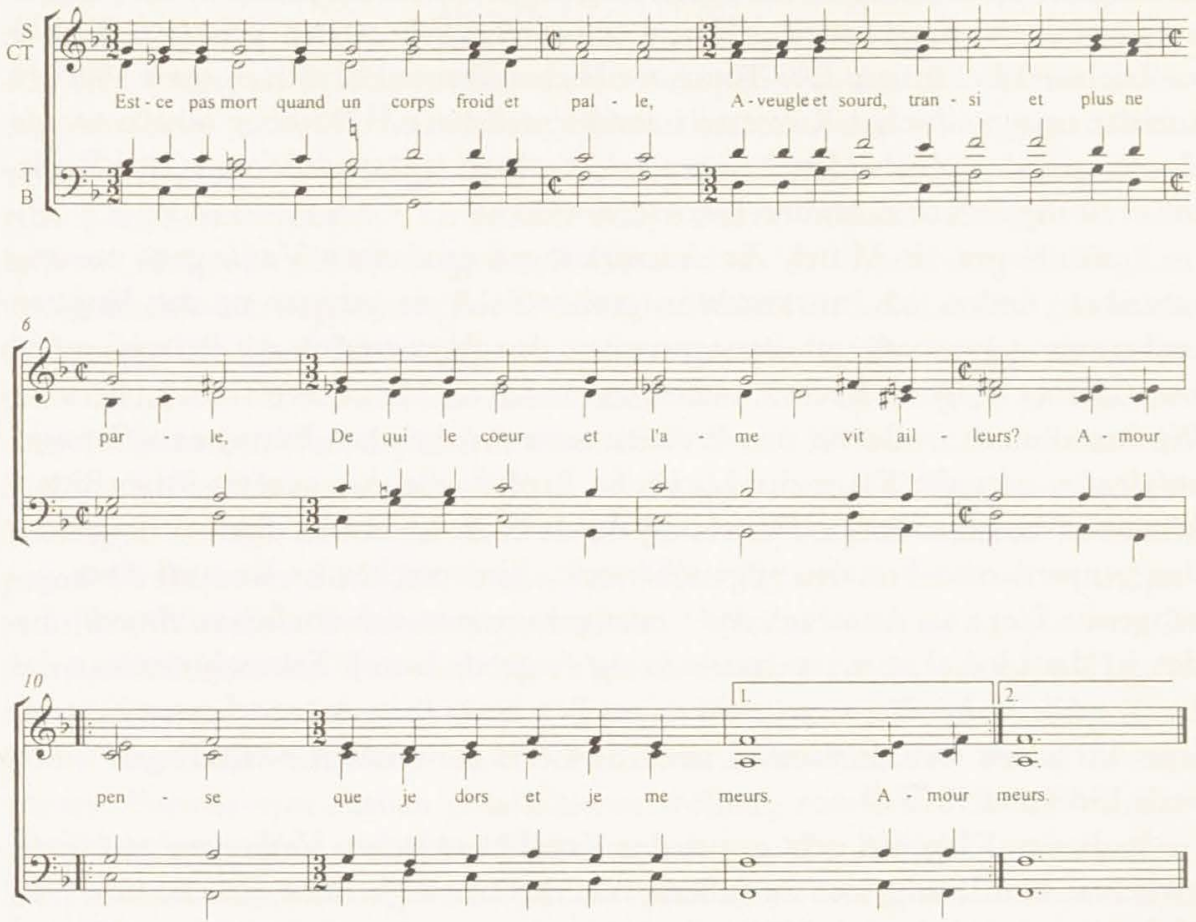

Notenbeispiel 1: Adrian Le Roy, "Es-ce pas mort", aus Second livre de chansons composé à quatre parties de plusieurs autheurs, Paris $1564,{ }^{2} 1569,{ }^{3} 1577$ (vollständiger Text siehe im Anhang, S. 110f.)

sungen eines Liebhabers in den Strophen 11-12 entsprechen einer Passage in Buch 1 (siehe Text 3 im Anhang, S. 112f.). Eine weit größere Übereinstimmung findet sich allerdings in Sideres Klage in Buch 13 (siehe Text 4 im Anhang, S. 113), denn auch Sidere wurde durch die Sorge um ihren Ruf davon abgehalten, der Leidenschaft nachzugeben, und beklagt ihren Mangel an Mut, der sie davon abhielt, mit ihrem Verehrer Rogel zu sprechen, um ein Stelldichein zu arrangieren. Wie die Sängerin von »Est-ce pas mort«, wütet Sidere gegen die Ehre, die sie als »Henker und Mörder« liebeskranker Frauen verdammt.

Das Bindeglied zwischen diesen Äußerungen weiblicher erotischer Sehnsucht ist die konsequente Dialektik des regulierenden Verständnisses von Ehre und ihrer Ansprüche, ein gängiger Aspekt in den Textpassagen weiblicher Figuren, sei es in den Liederbüchern wie auch im Amadis. Es fällt nicht schwer, Motive für die obsessive Wiederholung und Ausarbeitung dieses Themas im Ro- 
man und den verwandten lyrischen Gattungen zu finden. Der Widerstand der weiblichen Charaktere gegen die Angriffe der Männer auf ihre Ehre gibt den Liebesepisoden das Konstruktionsschema der >klassischen Ritterfahrt, wie es sich auch im Heldenepos findet. Je länger und stärker die Verteidigung der Frau, desto rühmlicher der letztendliche Sieg des Helden über ihre Bedenken. Doch bieten sich in einem solchen Schema auch deutliche Vorteile für die Frau: In einer Erzähltradition, die den meisten Frauen eine Teilnahme am echten Kriegsgeschäft verwehrt, erlaubt ihnen die Spannung zwischen Liebe und Ehre, Heldinnen eines inneren Kampfes zwischen Gefühl und Willen zu werden. Auf metaphorischer Ebene beweisen sie damit den gleichen Mut wie die männlichen Figuren auf dem Schlachtfeld. In ähnlicher Weise erlaubt die Gattung des Klagegesangs den weiblichen Charakteren, die petrarkistische Position unerfüllter Sehnsucht einzunehmen, die normalerweise den männlichen Figuren vorbehalten ist. ${ }^{25}$ Der Imperativ des Verbergens jedoch, der stets und unvermeidlich die Äußerung der erotischen Wünsche von Frauen begleitet, gibt ihrer Erfahrung von erotischem Verlangen ein gänzlich anderes Gepräge als entsprechenden Erfahrungen bei Männern.

Diese Beziehungen zwischen Musik und Ritterroman können auf mehrfache, komplementäre Weise hergestellt werden. Die Bände mit »Schätzen« aus Amadis - Sammlungen mit den beliebtesten Textpassagen, durch die Abschnitte des Romans unabhängig von der Rahmenerzählung überlebt haben - bieten eine solche Möglichkeit: Die Liederbücher können als eine Art lyrischer »Tresor« betrachtet werden, eine Mittel, charakteristische Episoden des Romans in einer anderen Form festzuhalten. Eine weitere Vergleichsmöglichkeit bietet die Tradition lyrischer Einfügungen in Romanen, ein Verfahren, das bis weit ins Mittelalter zurückreicht. Die verschiedenen Abschriften mittelalterlicher Romane weisen unterschiedliche Einfügungen oder auch gar keine auf. Lyrische Passagen, mit oder ohne Noten niedergeschrieben, machen keinen unentbehrlichen Anteil eines Romans aus, sondern dienten als gängige Ausschmückung. Die Stücke in Liederbüchern des 16. Jahrhunderts lassen sich daher als eine Art lyrische Auszierung der Romane verstehen, durch das andere Druckmedium von ihnen isoliert; umgekehrt lässt sich der Roman als ein narratives Gerüst begreifen, innerhalb dessen solche Lieder einen Sinn ergeben. Das bedeutet, dass die Ritterromane dem Publikum des 16. Jahrhunderts Motive und den Hintergrund für den

25 In einem Fall, der Complainte der Sidonie in Buch 11 des Amadis, klagt die weibliche Figur sogar in Form eines Sonetts, das Petrarca nachgestaltet ist. Allerdings ist diese lyrische Form dadurch getarnt, dass das Gedicht wie ein Prosatext niedergeschrieben ist und nicht in Kursiven, wie bei anderen lyrischen Einfügungen im Roman üblich. Vgl. L'onziesme livre d'Amadis de Gaule, Paris 1554, fol. IIr. 
emotionalen Zustand boten, in denen Sängerinnen sich darstellten - ein Hintergrund, der die vokale Darstellung weiblicher Sexualität innerhalb bestimmter Modi und Stile legitimierte. In beiden interpretativen Szenarien hat das Lied die Funktion, den Roman in seiner emotionalen Essenz zu destillieren, wobei ihre Wirkung durch die expressive Macht der Musik verstärkt wurde. ${ }^{26}$

Derartige Beziehungen mögen offensichtlich scheinen, wenn wir den bekanntesten italienischen Parallelfall des 16. Jahrhunderts, den Orlando furioso von Ariost, und seine Umsetzung in Vokalkompositionen betrachten. ${ }^{27}$ Bislang hat man gezögert, sich des Romans als Hilfsmittel zu bedienen, um die Stellung des Liedes im frühneuzeitlichen Frankreich zu erforschen; zum Teil vielleicht, weil die Beziehung zwischen einem Prosaroman und gesungener Dichtung weniger leicht zu greifen ist als die unmittelbare Vertonung von Abschnitten aus einem Versroman wie dem Orlando furioso. Die Wechselbeziehung zwischen Prosa und gesungener Dichtung verlangte nach einem Kontext, der die Zirkulation von Bild und Stil zwischen den Gattungen erhellt. Offenbar bot der Salon der Comtesse von Retz ein solches Umfeld. Zudem diente der Salon als Rahmen, in dem ein weibliches Publikum in Wechselwirkung mit dem zeitgenössischen Ideal der adeligen Frau trat, die im Mittelpunkt dieser Verschmelzung musikalischer und literarischer Texte steht.

Die zeitgenössische Lesepraxis legte nahe, den Text durch Vorlesen in Klang umzusetzen. Dies galt in dieser Epoche als beliebter Zeitvertreib der Aristokratie. So haben sich mehrere Beschreibungen erhalten, wie Passagen aus Amadis laut vorgelesen wurden. Es ist gut möglich, dass Gohorys Übersetzung von Buch 13 auf diese Weise in den Gemächern der Widmungsträgerin vorgelesen wurde. Sowohl Marfires als auch Sideres Klagen aus Buch 13 wurden als eindrucksvoll genug empfunden, um in die Ausgaben der Thresors aufgenommen zu werden. Wenn also Abschnitte aus Amadis im Salon der Comtesse de Retz

26 In dieser Hinsicht nehmen die Airs des 16. Jahrhunderts die Rolle vorweg, die Crystal Kile den heutigen Pop-Songs über Liebe zuschreibt: »In the typical pop love song, the prescribed brevity of the form combines with the intense affectiveness of music and the constructed emotional ultimacy of romantic love to create an almost orgasmic, ecstatic sperfect love moment or a moment of sperfect romantic despair over love. (Crystal Kile, »Endless Love Will Keep Us Together: The Myth of Romantic Love and Contemporary Popular Movie Love Themes«, in: Popular Culture: An Introductory Text, hrsg. von Jack Nachbar, Bowling Green 1992, S. 419, Wiederabdruck in: Women and Romance: A Reader, hrsg. von Susan Ostrov Weisser, New York 2001).

27 Hierbei ist zu bedenken, dass der Salon der Comtesse de Retz nicht nur eine wesentliche Rolle in der Übersetzung und Adaption des Amadis spielte, sondern gleichzeitig auch ein Zentrum für genau denselben Vorgang bezüglich Ariost war. Vgl. J. Lavaud, Philippe Desportes (wie Anm. 8), S. 101, und R. Gorris, Je veux chanter (wie Anm. 8). M. Rothstein, Reading (wie Anm. 5), S. 37 und 110-114, vergleicht narrative Strukturen bei Ariost und im Amadis. 
laut vorgelesen wurden, dann gerade diese Klagen. ${ }^{28}$ Bewegte schon der Amadis seine Leserinnen so stark, dass sie sich zur klingenden Umsetzung des Romans angeregt fühlten, so forderten die Musikdrucke als Material für eine musikalische Ausführung ihr Engagement umso mehr heraus. In Form von Stimmbüchern oder als Bearbeitung für Lautentabulatur blieb ihnen der musikalische Inhalt unverständlich und unzugänglich, wenn der musikalische Text nicht durch das Eingreifen eines oder einer Ausführenden in Klang umgesetzt wurde. Adrian Le Roy bezeugt in seiner Widmung zum Livre d'airs de cour, dass Catherine die Stücke selbst vorzutragen verstand. ${ }^{29}$ Der Stil dieser Lieder - wie in Notenbeispiel 1 (siehe oben S. 102) - war auf die musikalischen Fähigkeiten aristokratischer Frauen zugeschnitten. Relativ einfach, oft auf Tänzen basierend und für die Ausführung auf der Laute oder einem Tasteninstrument geeignet, waren die Airs prädestiniert, die Atmosphäre weiblicher Anmut zu schaffen, die in den höfischen Anstandsbüchern so sehr empfohlen wurde. ${ }^{30}$

Wie aber gestaltete sich ihre Beziehung zum Text, wenn sie Romane vorlasen und höfische Lieder sangen? Das offene Ende der Amadis-Romane - ein Werk, das wie kein anderes seiner Zeit zum inneren Mitfühlen aufforderte und einen definitiven Schluss verweigerte - ermunterte Leserinnen und Leser, sich mit den Hauptpersonen zu identifizieren. Frauen konnten sich in ähnlicher Weise positionieren, wie Stevi Jackson es als charakteristisch für Konsumentinnen heutiger Massenproduktionsromane ansieht: Die Erzählung des Romans gibt ihnen einen Leitfaden, die Erzählung des eigenen Ich zu konstruieren. ${ }^{31} \mathrm{Im}$ 16. Jahrhundert war dieses Phänomen allerdings öffentlich weit anerkannter als

$28 \mathrm{Zu}$ Belegen, dass das laute Lesen zur Freizeitgestaltung der Aristokratie gehörte, vgl. L. C. Keating, Studies (wie Anm. 8), und mehrere Aufsätze in $A$ haute voix. Diction et prononciation aux XVT et XVHI siècles. Actes du colloque de Rennes ... 1996, hrsg. von Olivia Rosenthal, Paris 1998 (Actes et colloques du Centre de Philologie et de Littératures Romanes de la Faculté des Lettres de l'Université de Strasbourg, 52). Zu Beispielen für das laute Lesen von Passagen aus dem Amadis vgl. M. Rothstein, Reading (wie Anm. 5), und M. Simonin, La disgrâce (wie Anm. 2).

29 Prinzessin Marguerite de Valois, die zu den engsten Freundeskreis um Catherine zählte, war offenbar auch eine versierte Lautensängerin. Brantôme, Catherines Cousin und der Bruder einer ihrer Hofdamen, beschreibt Marguerites Begabung als Sängerin und Lautenistin; darüber hinaus gibt er Zeugnis, dass sie Gedichte verfasste und sie selbst vertonte. Vgl. Pierre de Bourdeille, seigneur de Brantôme, Eurres complettes, hrsg. von Ludovic Lalanne, Bd. 7: Rodomontades espaignolles, sermens espaignols, $M$. de la Noue, Retraictes de guerre, des dames, Paris 1874, S. 82.

30 Zu einer detaillierteren Darstellung vgl. J. Brooks, Courtly Song (wie Anm. 13), S. 198-201.

31 Stevi Jackson, "Love and Romance as Objects of Feminist Knowledge«, in: Making Connections: Women's Studies, Women's Movements, Women's Lives, hrsg. von Mary Kennedy, Cathy Lubelska und Val Walsh, Washington 1993, S. 260 (Wiederabdruck in: Women and Romance: A Reader, hrsg. von Susan Ostrov Weisser, New York 2001). 
in der heutigen Gesellschaft. Es gibt zahlreiche Nachweise dafür, dass sich adelige Französinnen immer wieder auf die Rolle romantischer Heldinnen einließen, nach der sie sich selbst stilisierten oder die ihnen von außen zugetragen wurde. ${ }^{32}$ Dass Catherine und andere weibliche Angehörige ihres Kreises solche Rollen nur zu gern übernahmen, lassen die romantischen Pseudonyme erkennen, welche die Frauen in ihrer Korrespondenz benutzten. Catherine nannte sich Dictynne oder Pasithée; besonders das letztere Pseudonym erinnert stark an die Namen im Amadis. ${ }^{33}$ Dieser Prozess, eine romantische Heldin zu »werden«, hatte besonders nachhaltige Auswirkungen auf die weibliche Gesangskunst, da die Stilisierung zu einer Figur aus dem Amadis zu neuen Äußerungen im Stil des Romans anregte. Indem man das gleiche Vokabular und die gleichen Bilder für die eigenen expressiven Bedürfnisse benutzte, verwischten sich die Grenzen zwischen den Welten des Romans und des höfischen Aufführungskontexts. ${ }^{34}$

In ähnlicher Weise ermutigten zeitgenössische Ideale musikalischer Interpretation Sängerinnen dazu, in die Rollen, die der Text erschuf, hineinzuschlüpfen und die Zuhörer von ihrer Identifikation mit dem Inhalt zu überzeugen. Das orphische Bild des Zuhörers, der von der Leidenschaft des Textes und der Musik gefesselt wird - symbolisiert im Bild des göttlich inspirierten Orpheus -, war das meist verbreitete Mittel, eine erfolgreiche musikalische Ausführung zu beschreiben. Catherine selbst wird in zeitgenössischen Gedichten als weiblicher Orpheus geschildert. Le Roys Livre d'airs de cour eröffnet mit einer Vertonung von »Le ciel qui fut grand donneur«, einem Lied, dessen prominente Platzierung vermuten lässt, dass es an die Widmungsträgerin des Buchs gerichtet ist. Im Gedicht wird die Stimme der Dame mit der Harfe des Orpheus verglichen, die fähig sei, das Herz, den Körper und die Seele des Dichters nach Belieben zu bewegen. ${ }^{35}$ Zudem ist ein Bericht über eine musikalische Darbietung Catherines erhalten, in dem ihr Publikum überzeugt war, sie stimme einen Klagegesang an,

32 Marguerite de Valois wurde wiederholt mit Niquée gleichgesetzt, einer zentralen Figur im $A$ madis. Gohory verglich Catherine de Clermont mit Pentasilée, einer der Heldinnen in Buch 13. Wie Rosanna Gorris gezeigt hat, stellt Gohory Catherine in ähnlicher Weise der Pentasilée gleich wie er sich selbst als Lehrer des Helden Sylves de la Selve in das Buch einschreibt. Vgl. R. Gorris, Pour une lecture (wie Anm. 9), S.151-154.

33 J. Lavaud, Philippe Desportes (wie Anm. 8), S. 88-93, bietet eine Liste der Pseudonyme, die im Salon benutzt wurden, und identifiziert die Frauen, denen sie zugeordnet waren. Catherine hat diese Pseudonyme in ihrer Korrespondenz mit Henriette de Clèves oft für sich selbst benutzt. Vgl. Jullien de Pommerol, Albert de Gondi (wie Anm. 8), S. 204.

34 Zum Begriff der »Vokalität« vgl. die Einleitung der Herausgeberinnen zu Embodied Voices: Representing Female Vocality in Western Culture, hrsg. von Leslie C. Dunn und Nancy A. Jones, Cambridge 1994, S. If.

35 Der Text ist wiedergegeben bei J. Brooks, Courtly Song (wie Anm. 13), S. $37 f$. 
um ihre eigene Sehnsucht nach einem fernen Geliebten auszudrücken. Dieser Bericht findet sich als anonymer Text in Catherines Gedichtsammlung, einer Handschrift, die um 1574 für sie erstellt wurde. ${ }^{36}$ Der Dichter beschreibt, wie sie die Laute spielt und ihre »heimlichen Seufzer « zum musikalischen, akustisch fassbaren Ausdruck ihrer Sehnsucht werden (siehe Text 5 im Anhang, S. 114). ${ }^{37}$ Paradoxerweise nehmen das Schweigen und die Heimlichkeit, die dieser und andere Texte wiederholt als wesentliche Komponente der erotischen Erfahrung adeliger Frauen hervorheben, hier eine klingende Form an, die für die Ohren anderer bestimmt ist.

Die Erwartung, dass die Romane ein Modell für das Leben von Frauen bieten, konnte allerdings auch Ängste wecken. Die Vorstellung, dass Romane und Lieder zu unkeuschem Verhalten ermutigten, war im späten 16. Jahrhundert weit verbreitet, da das Auftreten romantischer Heldinnen immer unvereinbarer mit dem vorherrschendem moralischen Klima in der Zeit konfessioneller Auseinandersetzungen erschien. ${ }^{38}$ Während man jedoch im 16. Jahrhundert in erster Linie danach fragte, ob die Romane illegitime sexuelle Aktivität ermutigten, stellen Frauenforscherinnen heute andere Fragen. Stellten Lieder und Romanzen eine hemmende oder eine befreiende Kraft im Leben adeliger Frauen dar? Die beste Antwort dürfte beides berücksichtigen. Der Roman und verwandte lyrische Gattungen boten manchen Adeligen eine willkommene Gefühlspalette, da sie ihnen einen imaginären Raum für die Äußerung weiblichen Verlangens öffneten. Als Reflex und Vorlage für eine spezifisch weibliche Vokalität boten Roman und Lied eine Vielfalt an Möglichkeiten zur aktiven Teilnahme von Leserinnen und Sängerinnen am Ausdruck von Gefühlen durch das Medium der Musik.

Diese Beobachtung scheint umso frappierender, wenn man sie auf Lieder und Textpassagen anwendet, in denen es um die schweigende Hinnahme von Verlangen und Leidenschaft geht. Weibliche Sexualität, die rhetorisch als Schweigen versinnbildlicht wurde (was schon in textlicher Hinsicht ein Problem darstellt), wird zu einem noch gravierenderen Paradox, wenn reelle Frauen in der reellen Welt diesem Schweigen eine Stimme verleihen. Die Artikulation des Schweigens im Klang verlieh Frauen die Macht, ihr Verlangen durch die Identi-

36 Zur Datierung und zum Inhalt von Paris, Bibliothèque nationale, fond fr. 25455 vgl. J. Lavaud, Philippe Desportes (wie Anm. 8), S. 82-93, L. C. Keating, Studies (wie Anm. 8), S. 107-123, und J. Brooks, La comtesse de Retz (wie Anm. 8). Ch. E. St-John, The Salon vert (wie Anm. 8), bietet umfassende Übertragungen aus der Handschrift.

37 Paris, Bibliothèque nationale, fond fr. 25455 , fol. $66^{x}$.

38 Eine detaillierte Untersuchung dieser zunehmenden Unvereinbarkeit bietet M. Rothstein, Reading (wie Anm. 5), S. 125-144. 
fikation mit der sehnenden Persona im Roman oder im Lied zu gestalten und öffentlich zu verkünden. Gleichzeitig bestätigte das ständige Heraufbeschwören der Ehre als Hintergrund für ihr Verlangen die sozialen Strukturen, die ihr Handeln regulierten und dafür sorgten, dass die weibliche Sexualität strenger Kontrolle unterworfen blieb. Romane und Lieder bewegten sich auf einem schmalen Pfad durch ein Netzwerk von strengen Geboten, die gleichzeitig verspottet und verstärkt wurden. Doch gerade diese Gratwanderung bot Frauen die Gelegenheit, ihren Leidenschaften eine Stimme zu verleihen, während sie gleichzeitig den sozialen Diskurs stützten, der ihr Schweigen als Ideal anpries.

\section{ANHANG}

Tabelle 1: Musikdrucke mit Widmung an Claude-Catherine de Clermont, Comtesse de Retz. Alle, wenn nicht anders vermerkt, in Paris bei Le Roy \& Ballard erschienen.

$1 \quad 1552$ Premier livre de chansons, en quatre volumes, nouvellement composées en musique à quatre parties, par M. Pierre Certon. Strophische Lieder in mehrstimmiger Bearbeitung.

2 (1552?) Second livre de guiterre, contenant plusieurs chansons en forme de voix de ville: nouvellement remises en tabulature, par Adrian Le Roy. Erstdruck verloren, erhalten in der Wiederauflage von 1556; zuerst veröffentlicht zwischen dem Erscheinen des Premier livre de tabulature de guiterre am 12. September 1551 und des Tiers livre de tabulature de guiterre von 1552. Enthält textierte einstimmige Melodien in Mensuralnotation, auf der gegenüberliegenden Seite Gitarren-Arrangements (Tabulatur) von strophischen Liedern, meistens aus (1).

31554 Second livre de chansons, nouvellement mises en musique à quatre parties, par bons et scavans musiciens. Überwiegend strophische Lieder in mehrstimmiger Bearbeitung, Le Roy, Certon, Maillard, Arcadelt, Mithou und Entraigues zugeschrieben.

41564 Premier livre de chansons composé en musique à quatre parties par M. Pierre Certon. Überarbeitete Aufl. von (1), vier Lieder daraus durch vier andere von Certon aus (3) ersetzt. 
51564 Second livre de chansons composé à quatre parties de plusieurs autheurs. Reprint 1569 und 1577. Stark überarbeitete Aufl. von (3), enthält 3 strophische Lieder von Le Roy zwischen Liedern von Nicolas.

6 (1567) Breve et facile instruction pour apprendre la tablature. Kein Exemplar erhalten.

$7 \quad 1568$ A briefe and easye instru[c]tion to learn the tableture ... englished (London: Rowbothome). Englische Übersetzung von (6).

81569 Chansons de P. de Ronsard, Ph. Desportes, et autres, mises en musique par N. de la Grotte. Reprint 1570, 1572, 1573, 1575 und 1580. Strophische Lieder in mehrstimmiger Bearbeitung.

91570 Musique de Guillaume Costeley, organiste ordinaire et vallet de chambre, du treschretien et tresinvincible roy de France. Enthält ein Widmungssonett von Costeley an Catherine de Clermont; lateinisches Gedicht von Jacques Gohory. Enthält eine Abteilung mit strophischen Liedern unter der Titel »Meslange de chansons en façon d'airs«.

10 (1570) Instruction de partir toute musique des huit divers tons en tablature de luth. Kein Exemplar erhalten. Catherine de Clermont gewidmet, Vorwort von Jacques Gohory. Möglicherweise in einer Neuauflage von (6) enthalten.

111571 Liore d'airs de cour miz sur le luth, par Adrian Le Roy. Catherine de Clermont gewidmet. Enthält textierte einstimmige Melodien in Mensuralnotation; auf der gegenüberliegenden Seite GitarrenArrangements (Tabulatur) von strophischen Liedern, meistens aus (8); 1 Stüick gemeinsam jeweils mit (5) und (12).

121573 Premier livre de chansons en forme de vau de ville composé à quatre parties, par Adrian Le Roy. Neue mehrstimmige Bearbeitungen von Liedern aus (1), (2), (3), (4) und (11) sowie 3 neue Stücke.

131574 A briefe and plaine Instruction to set all musicke of divers Tunes in Tableture for the Lute ... with a brief Instruction how to play on the Lute by Tablature ... also a third Booke containing divers new excellent tunes. All first written in french by Adrian Le Roy (London: Rowbothome). Englische Übersetzung von Stücken aus (6), (10) und (11), enthält eine Widmung an Catherine de Clermont und ein Vorwort von Jacques Gohory aus (10). 
1 Est-ce pas mort quand un corps froid et palle, Aveugle et sourd, transi et plus ne parle De qui le coeur et l'ame vit ailleurs: Amour pense que je dors et je me meurs.

2 Est-ce pas mort quand un autre a sa vie Qui fuit son bien et force son envye

Qui veut et n'ose appaiser ses douleurs.

\section{Amour ...}

3 Est-ce dormir quand sans cesse je veille, Et que l'amour en dormant me reveille, Pour me transir en regretz et en pleurs.

$$
\text { Amour ... }
$$

4 Est-ce dormir quand un desir me ronge Toute la nuit et que tousjours je songe Que je te baise, helas songes menteurs. Amour...

5 Certes c'est mort ou plus cruel martire Puis que les mortz ne souffrent rien de pire Que de finir par la mort leurs malheurs. Amour...

6 Mais moy je meurs et si vis tout ensemble Et sans mourir tousjours morte je tremble Pour ne jouir des biens qui me sont seurs.

Amour...

7 O vie, ô mort, o mon peu d'hardiesse Quand folle n'ose employer ma jeunesse Et que j'yverne mon printemps, et mes fleurs.
1 Ist es nicht der Tod, wenn ein kalter, bleicher Leib, blind und taub, erstant nicht länger spricht, dessen Herz und Seele woanders leben?

LIEBE denkt, ich schlafe, doch sterbe ich.

2 Ist es nicht der Tod, wenn ein anderer das eigene Leben besitzt, einer, der davor flieht, Freuden zu genießen und seinem

$$
\text { Verlangen Gewalt antut, }
$$

der Wünsche hegt, aber nicht wagt, seinen Schmerz zu

$$
\text { stillen? }
$$

$$
\text { LIEBE ... }
$$

3 Ist es Schlaf, wenn ich ohne Unterlass wache und wenn mich die Liebe im Schlafe weckt, um mich mit Reue und Tränen zu durchdringen? LIEBE ...

4 Ist es Schlaf, wenn mich ein Begehren zernagt die ganze Nacht, und ich immer träume, dich zu küssen? Ach, trügerische Träume! LIEBE ..

5 Gewiss ist es Tod oder noch grausamere Tortur, denn selbst die Toten erleiden nichts SChlimmeres, als bis sie durch den Tod ihr Unglück beenden. LIEBE ...

6 Doch ich, ich sterbe und lebe doch zugleich, und ohne zu sterben bin ich stets tot und bebe, weil ich nicht die Freuden, die mir (eigentlich) sicher sind, genießen kann LIEBE ...

7 O Leben, o Tod, o mein eigner Mangel an Kühnheit, da ich Irrsinnige nicht meine Jugend zu nutzen wage und Winter über meinen Frühling und meine Blumen kommen 
8 Donques pour vivre, il faut que je jouisse Mais cest honneur ne veult que j'acomplisse Heur plus heureux du plus grand de mes heurs. Amour ...

9 Mortel honneur helas la patience De me veoir morte en fuiant jouissance Me fait souffrir mil' autres deshonneurs. Amour ...

10 Las! qui me veoit plus mourante que vive Juge fort bien ma volunté craintive Et que la peur refroidit mes challeurs. Amour ...

$11 \mathrm{O}$ bras trompez, qui durant les nuitz sombres Allez au lit n'accollans que les umbres $\mathrm{Voz}$ doitz me soyent fidelles serviteurs. Amour ...

12 Las que celuy qui fait que je palice Me feroit bien plus que vous de service Mais las je n'ose approcher ses grandeurs. Amour...

13 Il m'est advis si tost que j'en approche Las que desja un chacun me reproche Que j’ay reçeu le bien de ses doulceurs. Amour...

14 Mais par despit la peur et l'amour forte M'endormiront bien tost de telle sorte Qu'un autre mort finira mes douleurs. Amour ...

15 Dont finiront cent mille mortz pour une
8 Darum muss ich, um zu leben, fröhlich sein,

doch diese Ehre lässt mich nicht das Glück

erreichen, das mehr als mein größtes Glück wäre.

$$
\text { LIEBE ... }
$$

9 Tödliche Ehre, ach, mich geduldig tot zu sehen, weil ich die Freuden fliehe,

lässt mich tausend andere Unehren erleiden. LIEBE ..

10 Ach! wer mich mehr sterbend als lebendig sieht, möge mein geängstigtes Wollen wohl beurteilen, und dass Angst meine Hitze kühlt. LIEBE ...

11 O betrogene Arme, die ihr in den dunklen Nächten im Bette nur Schatten umhalsen werdet, lasst eure Finger mir treue Diener sein. LIEBE ..

12 Ach, der, welcher mich erbleichen lässt, würde mir weit größere Dienste tun als ihr, doch, ach! ich wage nicht, mich seiner Erhabenheit zu nähern. LIEBE ...

13 Ich glaube, dass, wenn ich mich ihm nähere, mich schon jeder tadelt, im Glauben, dass ich die Freuden seiner Liebkosungen erfahren habe. $\angle I E B E$...

14 Doch dem zum Trotz werden mich Furcht und starke Liebe einschlafen lassen, und zwar in einer Weise, dass ein anderer Tod meinen Schmerz beendet. LIEBE ...

15 So werden hunderttausend Tode für eine Frau enden, und ich will durch den Tod über mein Schicksal und das Unglück meiner Tränen triumphieren. LIEBE ... 
Text 2: Le trezieme livre d'Amadis de Gaule, übersetzt von Jacques Gohory (Paris 1571), fol. 22'-22

... la gente Marfire demeura en si grand desplaisir ... qu'elle desiroit mourir de dueil tellement que quasi plus ne mangeoit, plus ne reposoit jour ne nuict en aucune maniere: dont sa beauté alloit fort decheant et amoindrissant. Elle en cheut au lit malade, où de jour à autre sa maladie augmentoit, jusques à ce que se voiant pres du riquet de la mort, print Cardonie sa damoiselle par la main et avecques grands sanglots luy commença à dire: Cardonie m'amie, vous sçavez bien que jamais je ne vous ay rien celé de ce que j'ay eu sus mon cueur, et moins ores le ferai-je. Pourtant vous devez sçavoir, m'amie, que la raison de mon honneur, ne la grandeur de ma beauté, ne la rigueur dont j’ay usé à l'endroit du vaillant Prince Filisel, n'ont peu avoir tant de pouvoir, que l'excellence de sa beauté n'ait tout mis soubs le pied, et moy reduitte au piteux estant que me voiez, Auquel je ne sens en moy force ne vertu de pouvoir plus gueres prolonger ma vie ...
... die liebliche Marfire verblieb in so groBem Unmut ... dass sie vor Schmerz zu sterben wünschte. So $a ß$ sie kaum noch und ruhte weder Tag noch Nacht. Dadurch verfiel ihre Schönheit und wurde sehr vermindert. Sie lag krank zu Bett, wo ihr Siechtum von Tag zu Tag schlimmer wurde, bis sie sich an der Schwelle des Todes sah. Da nahm sie ihre Dienerin Cardonie bei der Hand und begann, ihr mit heftigem Schluchzen zu sagen: Cardonie, meine Freundin, Ihr wisst wohl, dass ich Euch nie etwas von dem verborgen habe, das ich in meinem Herzen bewege, und umso weniger werde ich dies nun tun. Doch müsst Ihr wissen, meine Freundin, dass weder meine wohlbegründete Ehre, noch meine große Schönheit, noch die Strenge, die ich gegen den mächtigen Prinz Filisel habe walten lassen, die Macht hatten, seine vortreffliche Schönheit davon abzuhalten, alles unter seinen Füßen zu zertreten und mich in diesen bedauernswerten Zustand zu versetzen, in dem Ihr mich seht und in dem ich nicht länger die Kraft oder Tugend verspüre, mein Leben weiter zu führen ...

Text 3: Le premier livre d'Amadis de Gaule, übersetzt von Nicolas de Herberay des Essarts, hrsg. von Hugues Vaganay, 2., erweiterte Aufl., hrsg. von Yves Giraud, Paris 1986, Bd. 1, S. 10 f.

Le temps estoit lors gracieux et serein, la lune belle et luysante, qui donnoit clarté aux deux damoyselles. Mais certes l'une avoit plus d'occasion d'estre contente que l'aultre, qui eust tresvoluntiers pris ce bien, ou ung semblable pour elle mesme, si elle en eust eu moyen, et tant en donnoit de cognoissance, que Elisene voyoit bien, qu'il n'y avoit faulte que de executeur pour y satisfaire, car ceste Dariolette, sentant en son esperit l'ayse prochain, que debvoit recevoit celle, qu'elle conduisoit,
Das Wetter war nunmehr angenehm und heiter, der Mond schön und leuchtend, was den beiden Mädchen Licht spendete. Doch hatte die eine sicherlich mehr Grund, zufrieden zu sein, als die andere, die mit größtem Vergnügen dieses Gut, oder ein ähnliches, für sich genommen hätte, wenn es ihr möglich gewesen wäre, und sie zeigte dies so deutlich, dass Elisene klar erkannte, dass nur einer, der es ausführt, nötig wäre, um sie zufrieden zu stellen, denn diese Dariolette, die in ihrem 
ne se povoit tenir de luy manier, puis les tetins, puis les cuysses et quelque chose d'advaintaige, et de trop vehemente ardeur souspiroit souvent, tout ainsi que si elle eust deu participer à ce bien futur de la princesse Elisene, à laquelle elle disoit: Helas madame, que heureulx est le prince, par lequel vous recevrez ceste nuict tant de plaisir.

Text 4: Le trezieme livre d'Amadis de Gaule, übersetzt von Jacques Gohory (Paris 1571), fol. $96^{\vee}-97^{\vee}$

Specialement Sidere vivoit en grieve desplaisance de ne luy [Rogel de Grece] avoir plustost ottroyé son amoureuse requeste, se plaignant en ses regrets de l'honneur, comme de bourreau, comme de meurdrier des miserables amantes, principalement de celles de son estat royal qui s'y estimoient plus obligées pour servir d'exemple aux autres. Ha (disoit elle à par soy) que ne luy avois je tranché le mot à notre arrivée de trouver le lieu de commodité, dont tant il m'importunait que avec l'obligation de ma delivrance, je pouvois estre trop excusée de le consentir: Las (discouroit elle) ... je devois plustost sans attendre tant de dangers, tant de regards et conterolles ... le recompenser de ses bienfaits en la commodité du long voyage que nous faisions ensemble. Puis recommencoit, ha faux honneur, garde de la chasteté des Dames, il ne fut oncques de plus cruel tiran que toy qui les gesnes, tourmentes et fais mourir à petit feu, $\mathrm{O}$ que je luy en escrirois volontiers ce que ne n'ay osé luy dire de bouche: la main estant plus hardie qui ne rougit point que la langue si prochaine de la face honteuse, mais la lettre escritte demeure, en danger d'estre veue et descouverte, portant suffisante preuve en soy de la condemnation de l'honnesteté.
Geiste das Vergnügen verspürte, das die Frau, welche sie begleitete, erfahren sollte, konnte sich nicht versagen, sich selbst mal an der Brust zu berühren, mal an den Schenkeln und noch woanders, und in ihrem allzu glühenden Feuer seufzte sie öfters, als ob sie gerade an dem künftigen Vergnügen der Prinzessin Elisene Teil gehabt hätte, welcher sie sagte: Ach, Madame, glücklich der Prinz, durch den Ihr heute Nacht solche Freuden erfahren werdet.
Vor allem lebte Sidere in schmerzlicher Reue, dass sie den amourösen Annäherungen des Rogel de Grece nicht doch stattgegeben hatte, und beschuldigte in ihren Klagen ihre Ehrenhaftigkeit als einen Henker, als Mörder armer liebender Frauen, vor allem solcher ihres königlichen Standes, die sich mehr als andere verpflichtet fuihlten, ein gutes Beispiel zu geben. Ach, sagte sie sich, dass ich ihm nicht rundweg das zugesagt habe, als wir hier ankamen, um einen angenehmen Platz zu finden, worum er mich so bestürmte und wofür ich - angesichts der Verpflichtung durch meine Rettung - nur zu gut zu entschuldigen wäre. Ach, fuhr sie fort, anstatt all die Gefahren zu erwarten, all die Blicke und Prüfungen, ... hätte ich ihn bei der günstigen Gelegenheit der langen Reise, die wir zusammen gemacht haben, belohnen sollen. Wieder begann sie: Ach, trügerische Ehre, Wächter weiblicher Keuschheit, es hat nie einen grausameren Tyrann als dich gegeben, der du sie fesselst, folterst und langsam zu Tode quälst! Oh, gerne würde ich ihm alles schreiben, was ich nicht laut $\mathrm{zu}$ sagen wagte, denn die Hand errötet nicht und ist tapferer als die Zunge, die dem verschämten Gesicht so nahe ist, doch der geschriebene Brief bleibt erhalten, in der Gefahr, gesehen und entdeckt zu werden, und enthält genügend Beweis für den Verlust der Ehre. 
Text 5: Paris, Bibliothèque nationale, fond fr. 25455 , fol. $66^{r}$

Encor n'est ce tout Pheur que j'eus aupres de vous, Oyant pinser le luth en ces acors si doux, Quand de soupirs secrets, les yeux levez en haut, La teste mi-baissée, et l'ame en son defaut, Vous sembliez regreter une absence lointaine.

Und dies ist noch nicht alle Freude, die ich in Eurer Gegenwart hatte und hörte, wie Ihr süße Akkorde auf der Laute schlugt, als Ihr, mit heimlichen Seufzern, Eure Augen hobet, den Kopf halb gesenkt und mit einer Seele voller Irrungen und Wirrungen, eine weit entfernte Abwesenheit zu bedauern schienet. 